\title{
INSPECTION OF GFRP COMPOSITES BY MICROWAVE NDE
}

\author{
Asha Gokul $^{1}$, K. Srinivas ${ }^{2}$, D. Radhika ${ }^{3}$ and J. Dhanasekaran ${ }^{4}$ \\ ${ }^{1,2,4}$ Scientist, ${ }^{3}$ Senoir Research Fellow, Directorate of NDE \\ Dr. APJ Abdul Kalam Missile Complex, Advanced Systems Laboratory, DRDO, \\ Hyderabad-500058, Telangana, India
}

\begin{abstract}
Fiber reinforced polymer (FRP) composites form a major structural part ofaerospace and defence applications. Non-destructive evaluation (NDE) plays an important role in assessing the quality and health monitoring of FRP composite structures.Defect detection of FRPcomposite structures are by different NDE techniques, such as ultrasonics, thermography, X-ray radiography. Depending on the type of material, their characteristic features and accessibility of the test object etc. suitable techniquesare employed. Microwave non-destructive evaluation (MWNDE) is an emerging NDE technique for characterizing and inspecting dielectric structures. Microwave NDE finds application in the areas of dielectric material characterization, determining thickness variation, defect detection and bond quality inspection.Inspection of glass fiber reinforced polymer (GFRP) composites by near-field reflection microwave NDE technique is presented in this paper. GFRP composite with known inserted defects such as inclusion and flat bottom holes are inspected to understand and establish Microwave NDE. Results of inspected structures by swept frequency reflection microwave NDE technique in the frequency range 8.2$12.4 \mathrm{GHz}$ (X-band) and $12.4-18 \mathrm{GHz}$ (Ku-band) respectively are presented. The position of the reflection characteristic curve indicates the depth of the defect in the inspected structure.
\end{abstract}

\section{KEYWORDS}

Microwave NDE, near-field reflection method, defect detection and swept frequency NDE technique

\section{INTRODUCTION}

The functional properties, namely mechanical, thermal and electrical, of Fiber reinforced polymer (FRP) composite can be tailor made to suit an application. This feature of FRP composites makes them a suitable choice for most of the aerospace and defence applications. FRP composite structures develop defects or damage during the fabrication process and inservice [1]. Assessing the quality and health monitoring of the composite structure is of primary concern from an intended application of the structure.Non-destructive evaluation (NDE) plays an important role in characterizing and confirming the quality of the product, for its functionality and applications. Ultrasonics, Thermography, X-ray radiography are the most common NDE techniques for evaluating the FRP composite structures. Depending on the type of material, their characteristic features and accessibility of the test object, suitable techniquesare employed [2].Microwave Non-destructive evaluation (MWNDE) is an emerging NDE technique for characterizing and inspecting the dielectric structures. Microwave NDE operates in the frequency range $1 \mathrm{GHz}-40 \mathrm{GHz}$ of the electromagnetic spectrum. The following features of microwaves makes it suitable and challenging NDE tool over the conventional NDE techniques [3]: 
- Ability to penetrate dielectric materials

- No couplant is required during testing

- Testing is done in either near-field or far-field of the probe

- Single sided (Reflection method) or two sided (Transmission reflection method) inspection

- Provides contact mode or non-contact mode of testing

- Cost effective inspecting setup

Areas of application of microwave NDE include dielectric material characterization, monitoring or determining thickness variation, defect detection and bond quality inspection. Inspection of Glass Fiber Reinforced Polymer (GFRP) composite with known inserted defects by near-field reflection microwave NDE technique is presented in this paper. GFRP composite laminates with known defects are considered to establish Microwave NDE technique in both Contact and Noncontact modes respectively. Results of inspected structures by swept frequency microwave NDE technique in the frequency range of $8.2-18 \mathrm{GHz}$ are presented.

\section{THEORETICAL BACKGROUND}

A dielectric material is defined as a non-conductor which stores charge from external electric field. A dielectric material is characterized by dielectric properties namely, dielectric constant and loss tangent at a particular frequency. When microwaves are incident on a dielectric material, part of the energy is reflected, part is transmitted through the material and the remaining is absorbed. The distribution of energy into these three categories is due to the variation in the dielectric properties of the material from that of the external medium. The interaction of microwaves with the dielectric material in the form of transmission, reflection and absorption is the basis for microwave NDE $[4,5]$.

Near-field reflection microwave NDE is employed for inspection of dielectric FRP composites. Further, testing can be done in either contact or non-contact mode. Dielectric material/structure backed by a conductor shown in Figure 1 (the testing configuration), where reflection coefficient, $S_{11}$ is the measurable parameter [3].Reflection coefficient consists of magnitude and phase information as a function of operating/testing frequency. For material with low dielectric properties, materials backed by conductor configuration are used to enhance the reflected signal. As the test configuration involves conductor backup, this leads to single-sided inspection of the structure. Figure 2 shows the standard X-band $(8.2-12.4 \mathrm{GHz})$ Open-ended rectangular waveguide $(\mathrm{OEWG})$ probe operating in dominant $\mathrm{TE}_{10}$ mode. For near- field measurements, a square flange with sides greater than one-wavelength in free space is a good approximation to the theoretical assumption of an infinite flange where fields exists within the radiating aperture [3]. To enhance the detection sensitivity, operating frequency incase of both contact and noncontact methods, and stand-off distance incase of non-contact method is optimized.

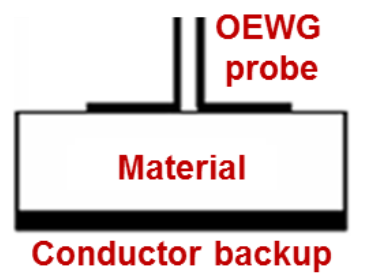

(a) Contact method

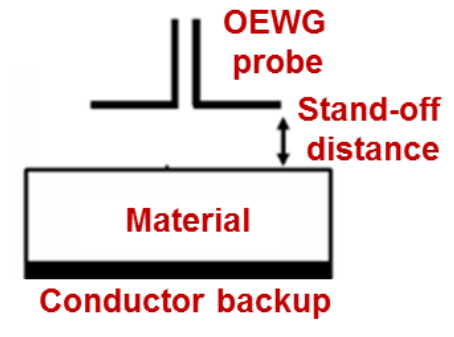

(b) Non-contact method

Figure 1.Near-field reflection microwave NDE test configuration 
International Journal Of Microwave Engineering (JMICRO) Vol.5, No.1, January 2020

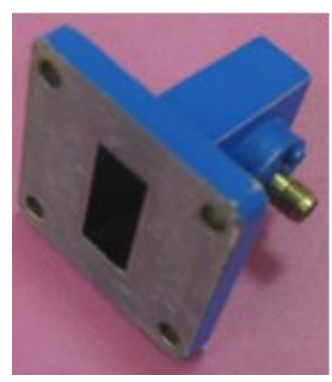

Figure 2. X-band (8.2-12.4GHz) Open-ended rectangular waveguide (OEWG) probe

\section{EXPERIMENT AND RESULTS}

The experimental setup for Near-field reflection microwave NDE in contact and non-contact modes are shown in Figure 3 and Figure 4 respectively. The setup consists of Keysight Vector Network Analyzer, coaxial cables, open-ended rectangular waveguide probe, waveguide calibration kit and sample under test backed by conductor [6]. The experimental setup is calibrated for the test frequency and the reflection coefficient of conductor is measured. The reflection coefficient of conductor consists of magnitude and phase, which is the reference.

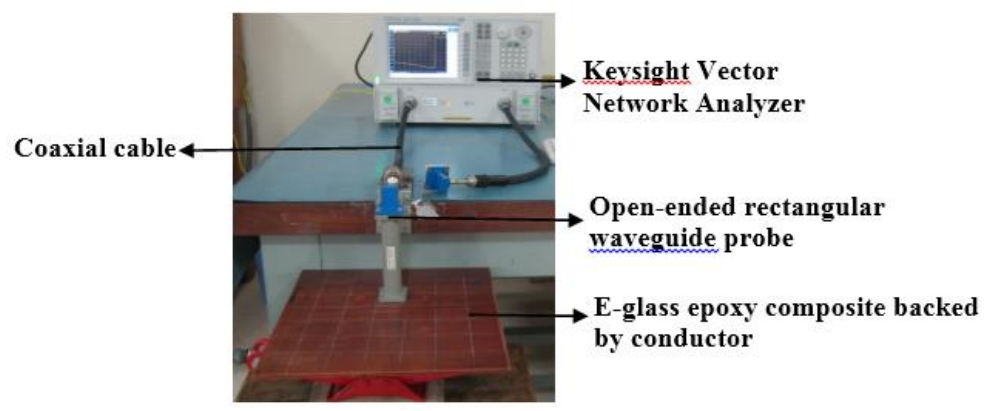

Figure 3. Near-field reflection microwave NDE in contact mode at X-band

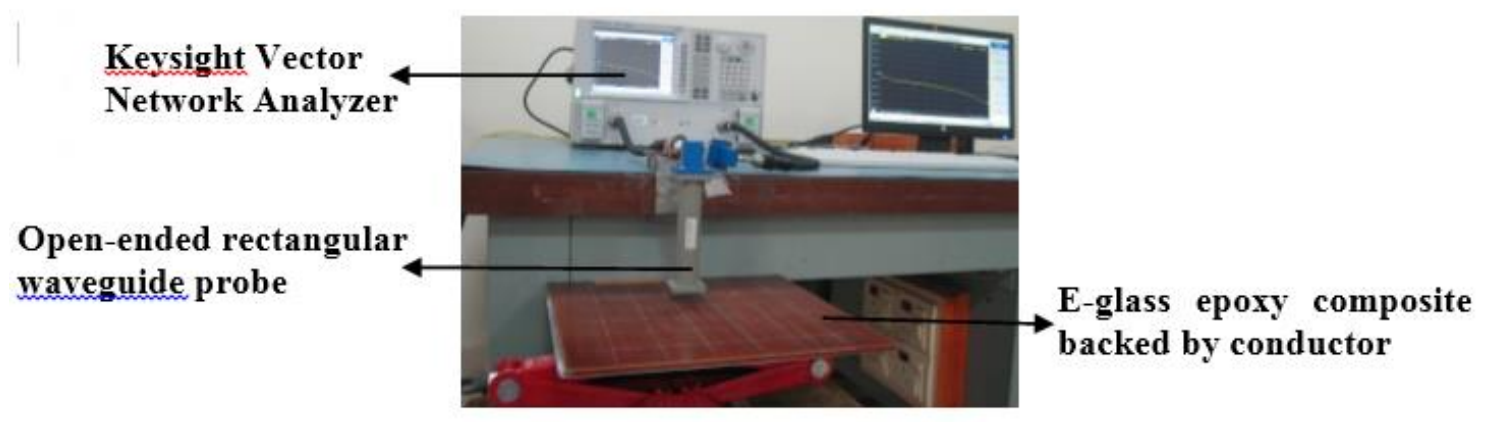

Figure 4. Near-field reflection microwave NDE in non-contact mode at X-band

To understand the interaction of microwaves with dielectric composites and establish the NDE technique for defect detection, E-glass epoxy composite laminate with known inserted defects are considered. The test laminates considered are (a) E-glass epoxy composite with inserted Teflon defects, (b) E-glass epoxy composite with flat bottom holes and (c) E-glass epoxy with flat bottom holes filled with carbon/ foam/ resin respectively. Inspection of each of the laminates is carried out by measuring the reflection characteristics, in both contact and noncontact modes respectively. Depending on the detection sensitivity, either magnitude or phase characteristics is an indicative parameter of the presence of defects. 


\subsection{Inspection of E-Glass Epoxy Composite with Teflon Inserts}

Figure 5 shows the configuration of the test sample, E-glass epoxy composite $(300 \mathrm{~mm} x$ $300 \mathrm{~mm} \times 5 \mathrm{~mm}$ ) with inserted Teflon defects. Inserted Teflon defects represent inclusionsin the host material, E-glass epoxy composite. The Teflon defects of different size are inserted at different depthin the composite. The size of Teflon inserts are $10 \mathrm{~mm}$ and $20 \mathrm{~mm}$ dia, $0.5 \mathrm{~mm}$ thick respectively.

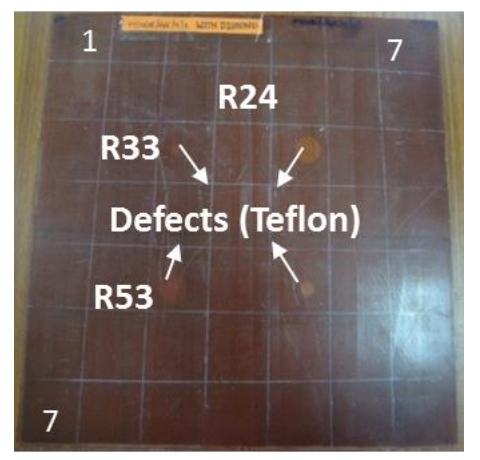

Figure 5. Configuration of E-glass epoxy composite with Teflon inserts

For manual inspection, the entire E-glass epoxy composite laminate is divided into regions based on the dimension of the OEWG probe. The reflection characteristics consisting of magnitude and phase for E-glass epoxy composite with inserted Teflon defectsare measured by Near-field reflection microwave NDE in contact mode. Once the experimental setup is calibrated, the reflection characteristics of aluminium plate aremeasured for reference. The sample backed by an aluminium plate is inspected by Open-ended rectangular waveguide probe in the frequency ranges of $8.2-12.4 \mathrm{GHz}$ (X-band) and $12.4-18 \mathrm{GHz}$ (Ku-band) respectively. The results of reflection magnitude and reflection phaseof the inspected laminate at Ku-band is shown in Figure 6 and Figure 7 respectively.

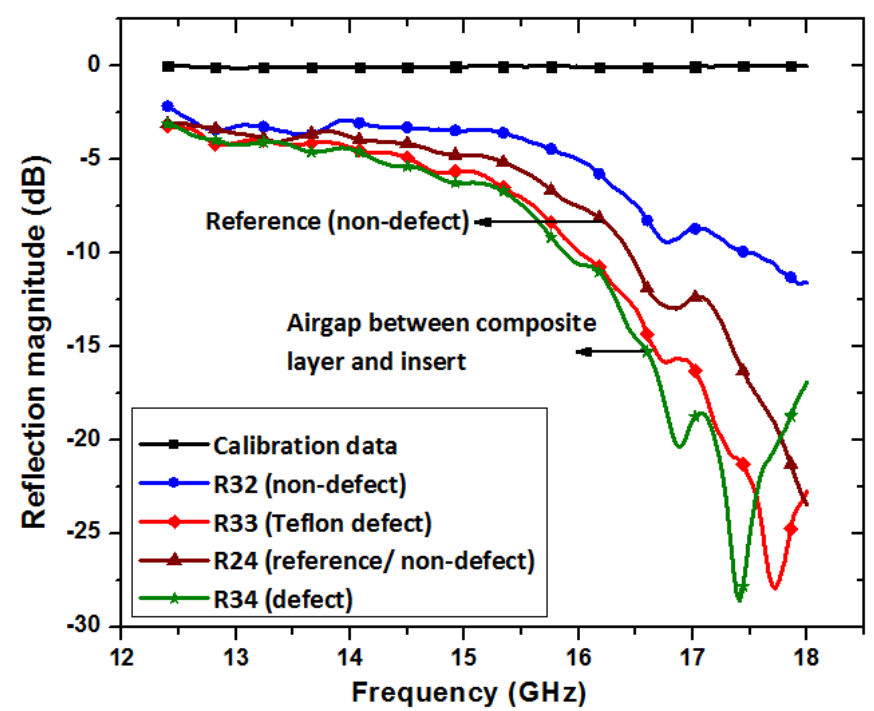

Figure 6. Reflection magnitude of E-glass epoxy composite with Teflon inserts at Ku-band 
International Journal Of Microwave Engineering (JMICRO) Vol.5, No.1, January 2020

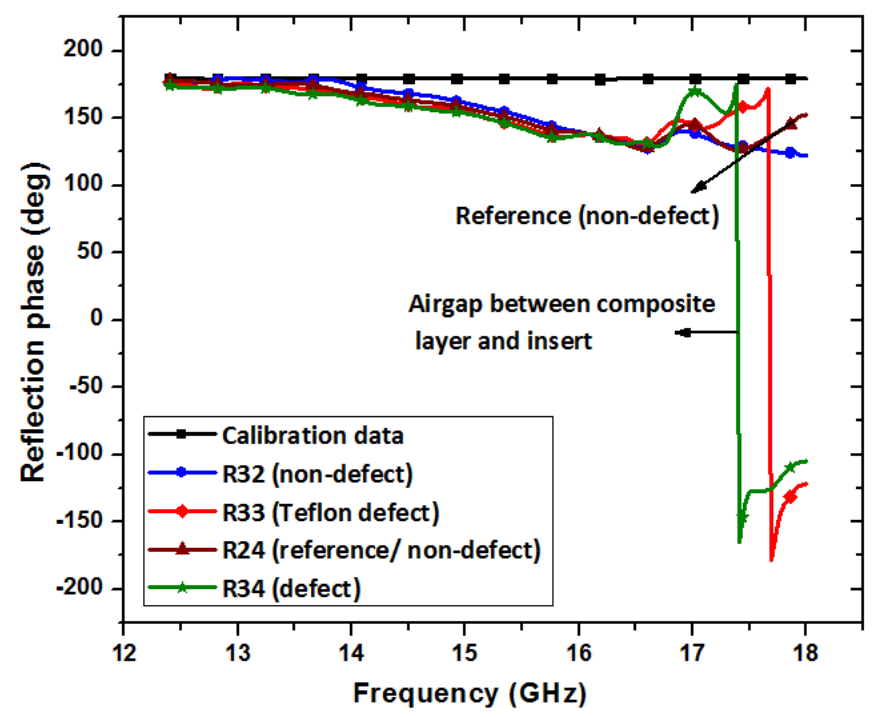

Figure 7. Reflection phase of E-glass epoxy composite with Teflon inserts at Ku-band

The reflection characteristics of a sample depend on the material's dielectric properties, material thickness and its response to frequency. The response of Aluminium plate, used as the backup for the test configuration is taken as the calibrated data. The response of non-defect region (R24, second row fourth column region) in the E-glass epoxy composite laminate is taken as the reference. Any deviation from the reference response indicates the presence of defect. Nearfield reflection microwave NDE technique detected all the four Teflon inserted defects, though only one Teflon defect (R33) is shown in the results. Air-gap between the composite layer and Teflon insert (R34) which occurred due to fabrication process is also detected by microwave NDE technique. During the inspection, the test frequency is swept and hence the technique is also called as Swept frequency reflection microwave NDE technique.For a given material dielectric properties and thickness, the sensitivity to detect the defects depends on the response of the material to the frequency. In case of E-glass epoxy composite with Teflon inserts, the detection sensitivity to detect all the four Teflon inserts is in the frequency range $16.5-18 \mathrm{GHz}$.

Microwave NDE results are correlated with results of conventional NDE techniques like aircoupled ultrasonics and thermography, respectively and found to be in agreement with respect to detecting all the four Teflon inserts. Only microwave NDE was able to detect the presence of air gap between the composite layer and the inserted defect. Figure 8 shows the air-coupled through transmission ultrasonic $\mathrm{C}$-scan $(1 \mathrm{MHz})$ results and Figure 9 shows the thermography results of the E-glass epoxy composite with Teflon inserts respectively.

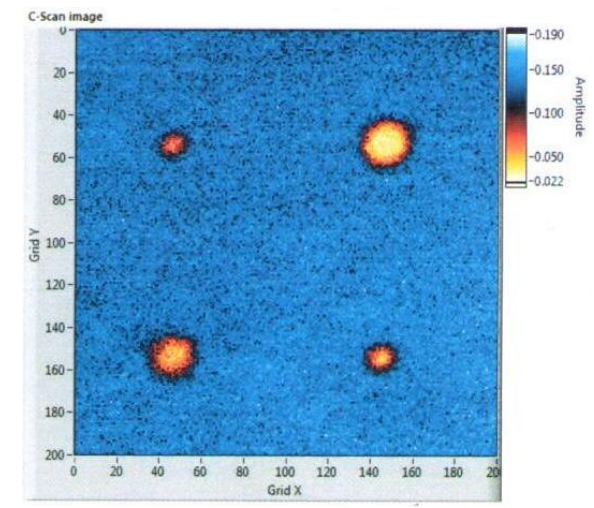

Figure 8. Air-coupled Ultrasonics C-scan (1MHz) results of E-glass epoxy composite with Teflon inserts 


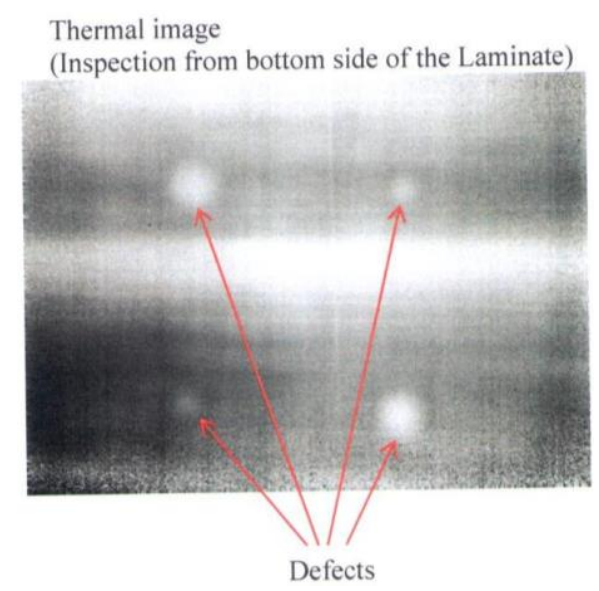

Figure 9. Thermography results of E-glass epoxy composite with Teflon inserts

\subsection{Inspection of E-Glass Epoxy Composite with Flat Bottom Holes}

Laminate with flat bottom holes are considered as standard defects in understanding and establishing an NDE technique. These represent voids, delaminations and disbond kinds of a defects. E-glass epoxy (GE) composite $(300 \mathrm{~mm} \times 300 \mathrm{~mm} \times 15 \mathrm{~mm}$ ) with flat bottom holes (3 noshaving 20mm dia) at different depth shown in Figure 10 are inspected by contact microwave NDE technique using portable Vector network analyzer. The defects are at a depth of $5.5 \mathrm{~mm}$, $4.5 \mathrm{~mm}$ and $3.7 \mathrm{~mm}$ respectively from the composite side. The experimental setup shown in Figure 11consists of Keysight Field Fox microwave network analyzer (Portable MNA), coaxial cables, open-ended rectangular waveguide probe, waveguide calibration kit and sample under test backed by conductor [3]. The experimental set-up is calibrated for the test frequency and the reflection coefficient of conductor is measured. The reflection coefficient of conductor consists of magnitude and phase, which is the reference.

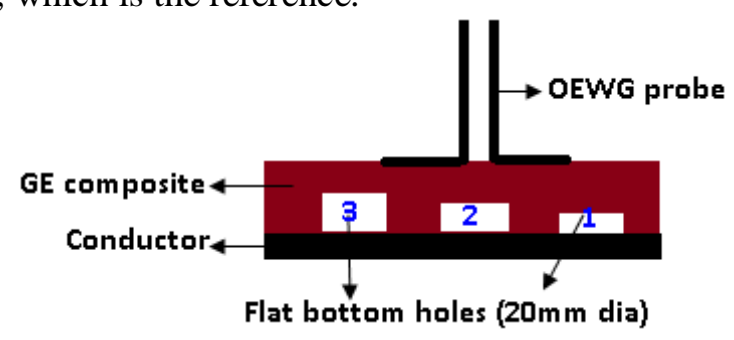

Figure 10. Configuration of E-glass epoxy composite with flat bottom holes at different depth

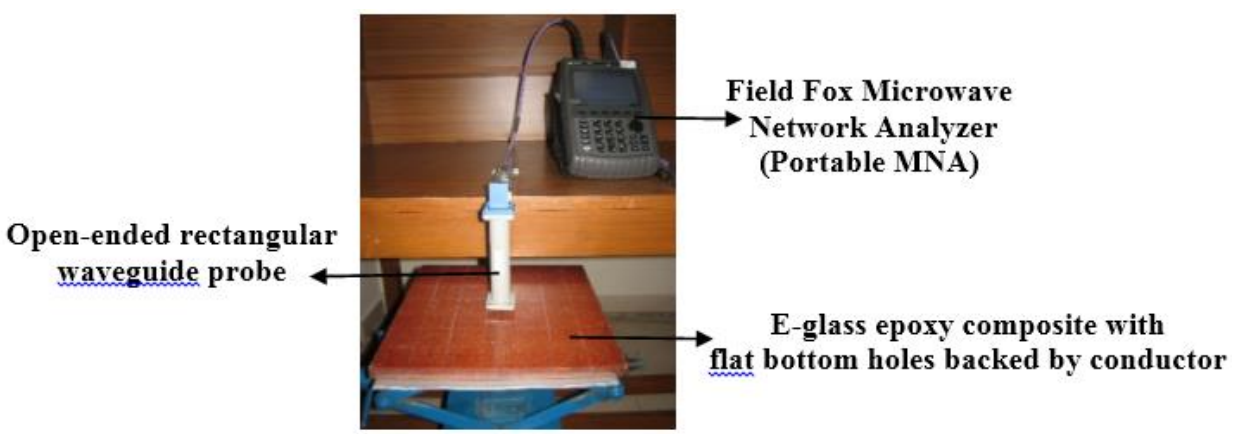

Figure 11. Near-field reflection microwave NDE in contact mode at X-band using portable VNA 
E-glass epoxy composite with flat bottom holes laminate is inspected manually from the composite surface side in the frequency range $(8.2-12.4 \mathrm{GHz})$. Figure 12 and 13 shows the reflection magnitude and reflection phase results of the inspected laminate, respectively. The response of composite without defect is the reference. Any deviation from the reference indicates the presence of defect.From the results, it is observed that phase is more sensitive to the presence of defect at different depths in the tested frequency range. The position of the curve indicates the depth of the defect in the laminate. The deeper the depth of the defect, the curve shifts to the lower frequency.

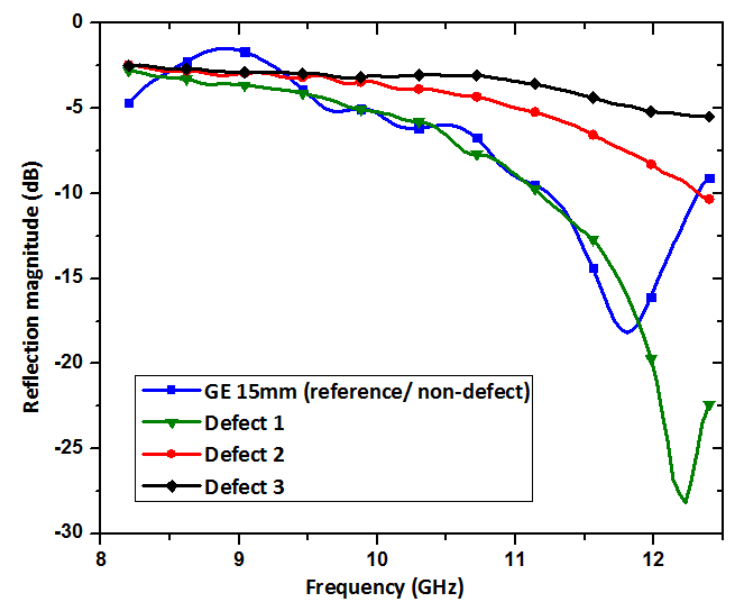

Figure 12. Reflection magnitude of E-glass epoxy composite with defects at X-band (Contact)

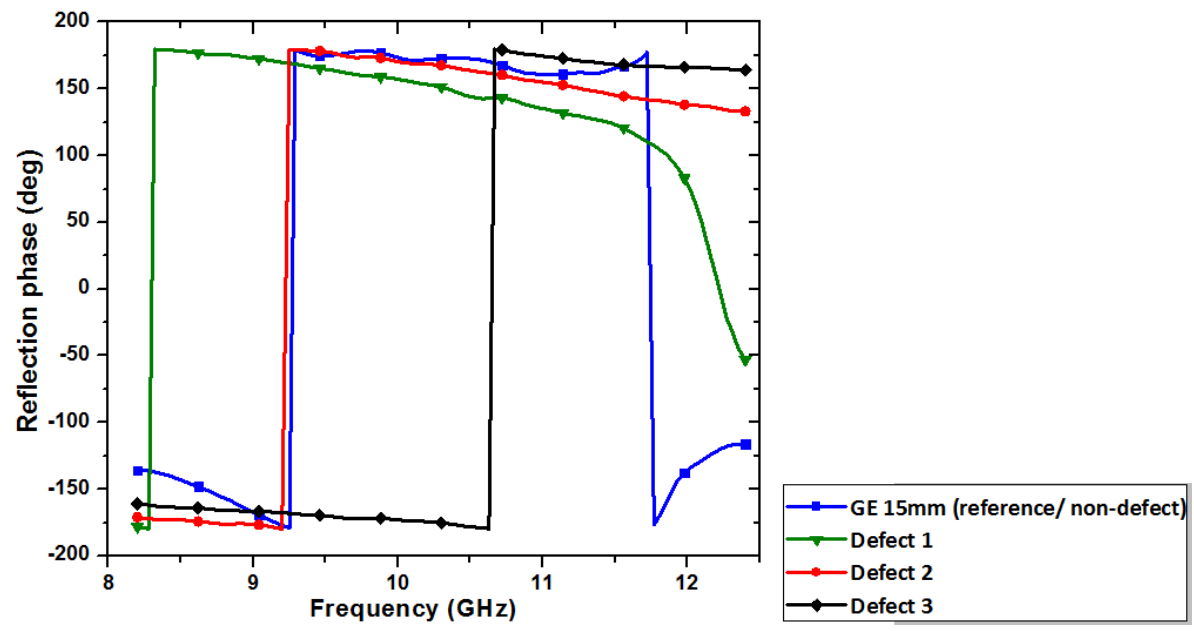

Figure 13. Reflection phase of E-glass epoxy composite with defects at X-band (Contact)

The E-glass epoxy composite laminate with defects is also inspected manually by Non-contact microwave NDE technique.The stand-off distance is varied manually from $0 \mathrm{~mm}$ (contact) to $7 \mathrm{~mm}$. The non-contact test configuration represents the contact test configuration of a two layered structure consisting of air and test material backed by conductor.In case of non-contact microwave NDE technique, for a given test material both frequency and stand-off distance must be optimised to enhance the defect detection sensitivity. For the composite laminate, the optimized stand-off distance is $1 \mathrm{~mm}$ in the frequency range $12.4-18 \mathrm{GHz}$ (Ku-band). The reflection magnitude and reflection phase results of composite laminate for the optimized standoff distance is shown in Figure 14 and 15, respectively. 

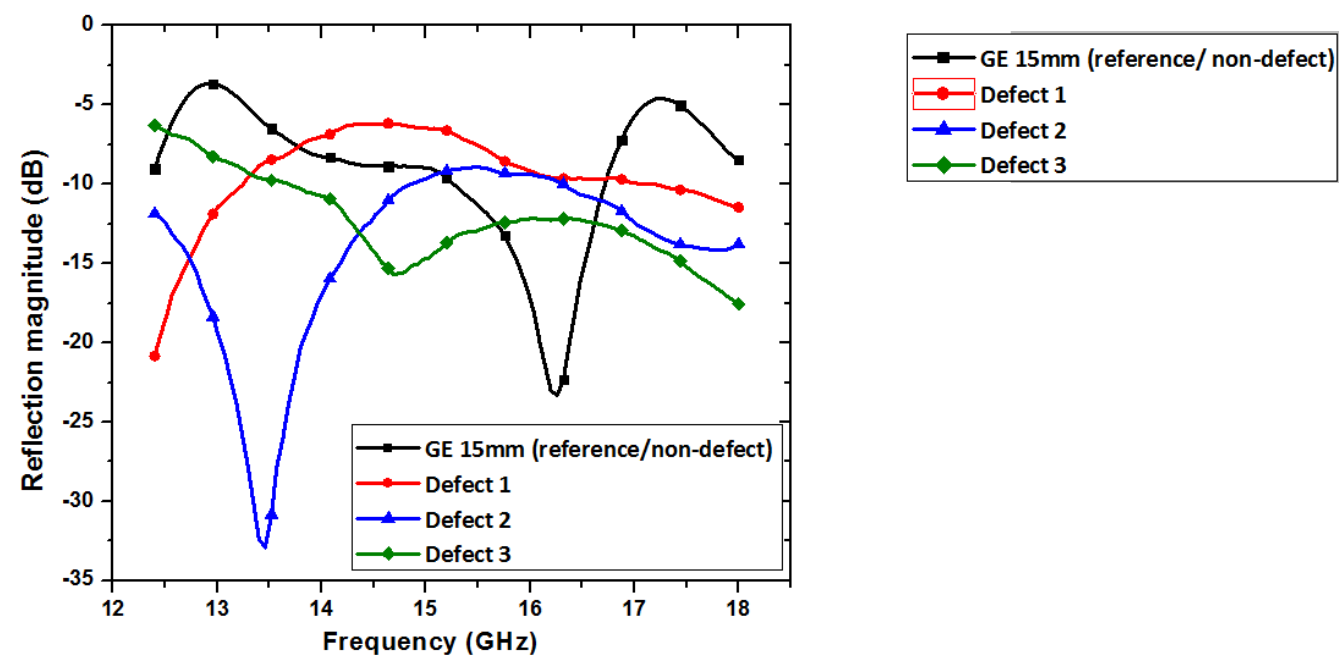

Figure 14. Reflection magnitude of E-glass epoxy composite with defects at Ku-band (Non-contact)

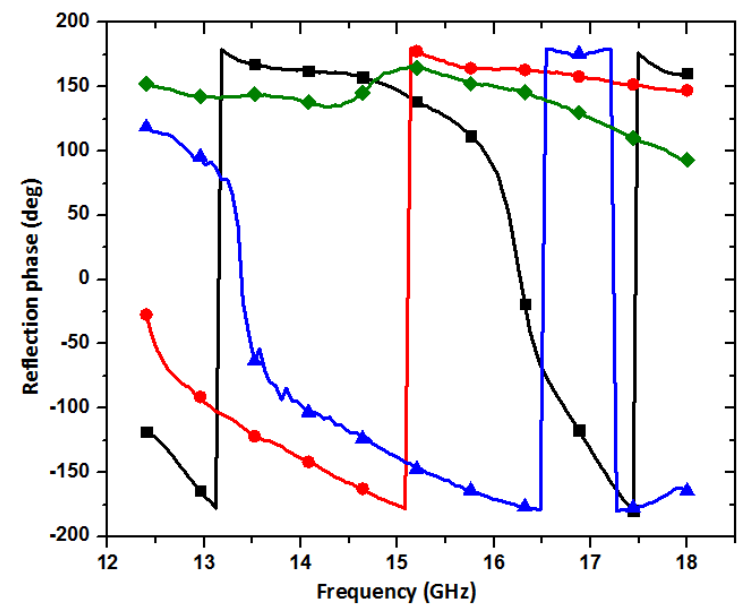

Figure 15. Reflection phase of E-glass epoxy composite with defects at Ku-band (Non-contact)

From the results, it is observed that the deeper the depth of the defect, the characteristic curve shifts to lower frequency. As the inspection is carried out manually, the mentioned results are pertaining to the composite region with defect, inspected from composite side. In this case, the rectangular probe dimension covers only the defect.

\subsection{Inspection of E-Glass Epoxy Composite with filled Flat Bottom Holes}

Swept frequency reflection microwave NDE technique is automated to provide microwave Cscan image of the inspected structure. Swept frequency reflection microwave NDE system consists of Keysight Vector network analyzer (VNA), XYZ scanner, coaxial cables, calibration kit, integration software, sample under test backed by conductor and open-ended rectangular waveguide probe. The integration software contains software for motion controlling of scanner and data acquisition. The microwave NDE system is shown in Figure 16. The microwave NDE system is developed for inspecting flat dielectric structures. 


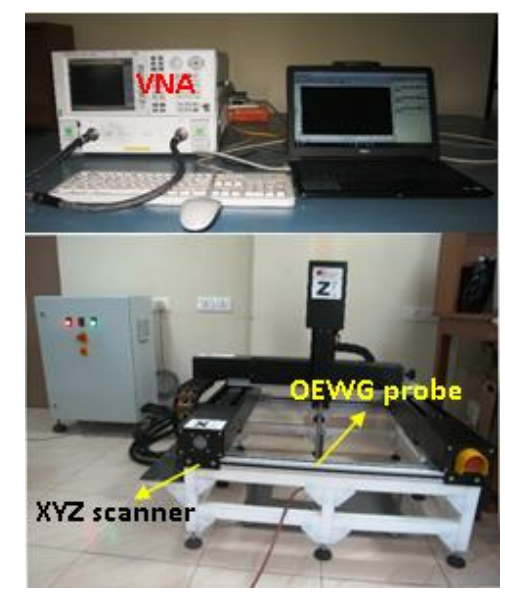

Figure 16. Swept frequency reflection microwave NDE system

E-glass epoxy composite laminate with flat bottom holes at different depth is inspected by swept frequency reflection microwave NDE system respectively in the frequency range $8.2-18 \mathrm{GHz}$. The flat bottom holes are filled by different materials- carbon fabric, foam and resin, respectively. Figure 17 shows the laminate configuration with multiple defects with the defect thickness. The structures to be inspected are scanned by the microwave NDE system for the frequency of interest and reflection data consisting of magnitude and phase are collected for each scan location along with the scan position (X and Y) respectively. From the reflection magnitude data, frequency which detects both,non-defect and defect regions is identified and the corresponding data is represented as a microwave C-scan image. Similarly, the microwave Cscan image from reflection phase data is obtained.

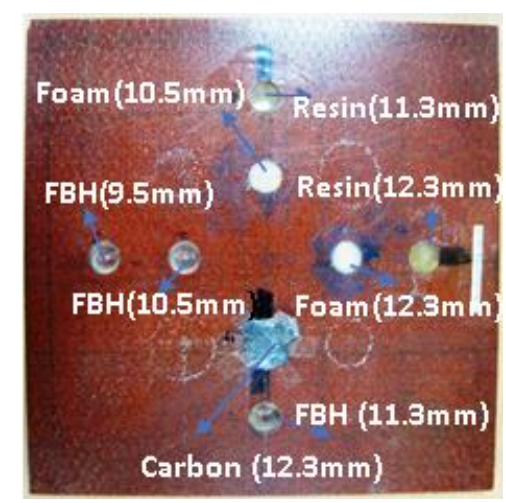

Figure 17. Configuration of E-glass epoxy composite with multiple defects

(flat bottom holes: empty, carbon fabric, foam and resin)

Figure 18 shows the microwave $\mathrm{C}$-scan image from the reflection magnitude data representing the quality of E-glass epoxy composite with multiple defects at a frequency of $13.1 \mathrm{GHz}$. Inspection of the laminate is done from composite side. The non-defect and defect regions are clearly distinguishable. For a given structure, the magnitude or phase response of non-defect and defect regions, respectively to a particular frequency will determine the detection sensitivity of the inspection technique. The results of defect detection by swept frequency reflection microwave NDE technique are in agreement with the results of thermography technique. Figure 19 shows the thermography image of E-glass epoxy composite with multiple defects. As the 
International Journal Of Microwave Engineering (JMICRO) Vol.5, No.1, January 2020

field of view in thermography is $300 \mathrm{~mm} \times 240 \mathrm{~mm}$, one flat bottom hole filled with resin is not detected.

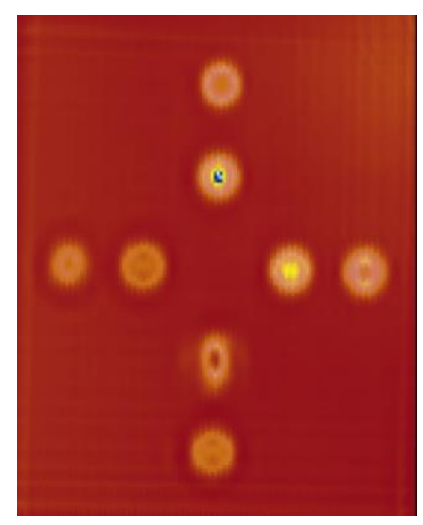

Figure 18. Microwave image of E-glass epoxy composite with multiple defects (filled flat bottom holes) at $13.1 \mathrm{GHz}$ (magnitude data) from Swept frequency reflection microwave NDE system

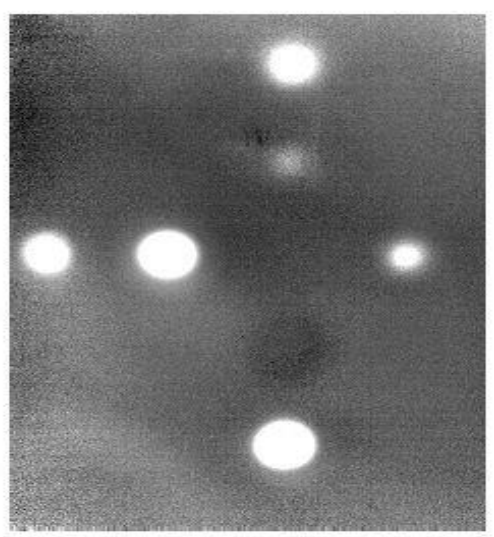

Figure 19. Thermography image of E-glass epoxy composite with multiple defects (Inspection area: $300 \mathrm{~mm} \times 240 \mathrm{~mm}$ )

\section{ConClusions}

Microwave non-destructive evaluation (MWNDE) is an emerging NDE technique for characterizing and inspecting dielectric composite structures. Microwave NDE is a useful tool for qualitative and quantitative analysis of quality inspection of GFRP composite structures.Microwave NDE provides single-sided and non-contact inspection over a range of testing frequencies. Swept frequency reflection microwave NDE is a complementary technique to evaluate dielectric GFRP structures for defect detection. For low loss dielectric GFRP composites, reflection phase is sensitive to the presence of defect. The response and position of the characteristic curveis an indicative parameter of the defect depth. The technique can be extended to inspect profiled or curved GFRP composite structures.

\section{ACKNOWLEDGEMENTS}

The authors are thankful to the Director, Advanced Systems Laboratory (ASL) for providing an opportunity, support and encouragement to carry out the work. 
International Journal Of Microwave Engineering (JMICRO) Vol.5, No.1, January 2020

\section{REFERENCES}

[1] R. A. Smith, Composite defects and their detection, Materials Science and Engineering, Vol-III, 2016.

[2] Peter. J. Shull, Nondestructive Evaluation-Theory, Techniques, and Applications, Marcel Dekker, Inc, New York, 2002.

[3] Reza Zoughi, Microwave Non-Destructive Testing and Evaluation, Non-destructive evaluation series volume 4, Kluwer Academic Publishers, 2000.

[4] N. Ida, Microwave NDT, Developments in Electromagnetic theory and applications, volume 10, Kluwer Academic Publishers, 1992.

[5] David. M. Pozar, Microwave Engineering, Second edition, John Wiley \& Sons, Inc, 1998.

[6] Asha Gokul, K. Srinivas, D. Radhika and J. Dhanasekaran, Application of Microwave NDE for Dielectric FRP Composites, International Conference on Composite Materials and StructuresICCMS 2017.

\section{AUTHORS}

Asha Gokul received Bachelor of Engineering (B. E) degree in Electronics and Communication Engineering and Masters of Engineering (M. E) degree in Microwave and Radar Engineering from Osmania University, Hyderabad, India. She is currently working as Scientist in Advanced Systems Laboratory, DRDO, Hyderabad. Her areas of work include Electromagnetic design of radomes, Dielectric matrial characterization and Microwave NDE.

K. Srinivas received $\mathrm{PhD}$ degree in Physics from Osmania University, Hyderababd, India. He is currently working as Scientist in Advanced Systems Laboratory, DRDO, Hyderabad. His areas of work include NDE of Composite structures and characterization of composites, ferroelctrics, microwave NDE

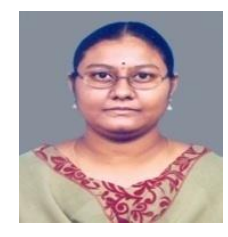
techniques. He has published over 28 international publications and conference papers.

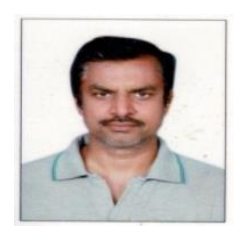

